\title{
EVALUASI TATA KELOLA TI PADA SEKRETARIAT DPRD PROVINSI SUMATERA SELATAN MENGGUNAKAN COBIT 5
}

\author{
Selvia Damayanti ${ }^{1}$, Edi Surya Negara ${ }^{2}$, Diana $^{3}$ \\ ${ }^{123}$ Program Pascasarjana Universitas Bina Darma \\ ${ }^{123}$ SelviaDmy@yahoo.com, e.s.negara@binadarma.ac.id, diana@binadarma.ac.id \\ Jl. A. Yani No. 12, Palembang, 30624, Indonesia
}

\begin{abstract}
Abstrak
Teknologi informasi telah lama digunakan oleh Sekretariat DPRD Provinsi Sumatera Selatan untuk mendukung setiap proses dalam bidang pemerintahan, Sekretariat DPRD Provinsi bertugas menyelenggarakan administrasi kesekretariatan dan keuangan, mendukung pelaksanaan tugas dan fungsi DPRD serta menyediakan dan mengkoordinasikan tenaga ahli yang diperlukan oleh DPRD Provinsi Sumsel dalam melaksanakan hak dan fungsinya sesuai dengan kebutuhan. Tujuan dari penelitian ini adalah untuk mengidentifikasi, mengetahui kondisi dan tingkat maturitas tata kelola IT serta memberikan rekomendasi perbaikan menggunakan framework COBIT 5. Hasil tingkat maturitas yang didapat dari nilai rata-rata penyebaran kuesioner berdasarkan domain EDM01, EDM 04, APO 01, APO 04, APO 07, BAI 02, BAI 08, DSS 01 dan MEA 01 adalah 2.24 yaitu Managed Process.
\end{abstract}

Kata Kunci: Tata Kelola IT, Cobit 5, Sekretariat DPRD Sumsel

\begin{abstract}
Information technology has long been used by the Secretariat of the DPRD of the Province of South Sumatra to support every process in the field of government, Secretariat of the DPRD of the Province of South Sumatra is in charge of organizing secretarial and financial administration, supporting the implementation of the tasks and functions of the DPRD and providing and coordinating experts needed by the DPRD of the Province of South Sumatra in implementing their rights and functions according to their needs. The purpose of this study is to identify, determine the condition and maturity level of IT governance and provide recommendations for improvements using the COBIT 5 framework. The results of the maturity level obtained from the average value of questionnaires are based on the domains EDM01, EDM 04, APO 01, APO 04, APO 07, BAI 02, BAI 08, DSS 01 dan MEA 01 which are 2.24 Managed Process.
\end{abstract}

Keywords: IT Governance, Cobit 5, DPRD of Province of South Sumatra Secretariat 


\section{PENDAHULUAN}

Penggunaan teknologi informasi pada saat ini sudah tidak bisa dihindarkan. Investasi teknologi informasi diharapkan mampu mendorong proses bisnis agar semakin efektif dan efisien. Oleh karena itu, diperlukan tata kelola dalam pemakaiannya mulai dari awal investai, implementasi hingga evaluasi. Grembergen, Haes \& Brempt menyatakan bahwa untuk memastikan bahwa investasi TI menghasilkan manfaat bisnis seperti yang diharapkan, maka organisasi sebaiknya memberikan perhatian pada pengelolaan investasi TI tersebut [1].

Teknologi informasi telah lama digunakan oleh Sekretariat DPRD Provinsi Sumsel untuk mendukung setiap proses dalam bidang pemerintahan. Sekretariat DPRD Provinsi bertugas menyelenggarakan administrasi kesekretariatan dan keuangan, mendukung pelaksanaan tugas dan fungsi DPRD serta menyediakan dan mengkoordinasikan tenaga ahli yang diperlukan oleh DPRD Provinsi Sumsel dalam melaksanakan hak dan fungsinya sesuai dengan kebutuhan. Dalam Susunan organisasi Sekretariat DPRD provinsi Sumsel terdiri atas 4 bagian yaitu, Umum, Persidangan, Keuangan, Humas dan Protokol. Setiap bagian memiliki tugas dan fungsi masing-masing yang saat ini sudah didukung teknologi informasi . Setelah penulis melakukan wawancara dan observasi ternyata ditemukan beberapa masalah seperti, tata kelola TI yang belum diatur secara rinci dan terstandar sehingga aktifitas yang didukung oleh TI belum maksimal, kerap terjadi kebingungan dan kesalahan dalam pengambilan keputusan. Backup database hanya menggunakan flashdisk atau hardisk milik pribadi, kebijakan hak akses terhadap SIMDA (Sistem Informasi Daerah) belum diatur secara konsisten dimana password dan id user masih bebas digunakan oleh setiap karyawan didalam satu divisi. SIMDA adalah sistem informasi yang disediakan untuk mendukung segala proses bisnis. Lalu permasalahan berikutnya adalah IT/IS yang digunakan belum terintegrasi secara maksimal padahal IT/IS tersebut saling berhubungan antar divisi.

Pentingnya tugas yang harus dilakukan oleh para Angggota Dewan tak luput dari dukungan administratif dari Sekretariat DPRD Prov Sumsel, oleh karena itu dibutuhkan evaluasi tata kelola IT secara berkala. Penulis akan menggunakan framework Cobit 5 dalam evaluasi dengan 30 responden pengguna IT. Cobit 5 mempunyai 5 domain, 37 proses dan 81 kontrol yang akan digunakan sebagai panduan untuk melakukan evaluasi tata kelola TI dan memberikan opsi-opsi kepada Sekretariat DPRD Prov Sumsel atas permasalahan yang ada serta mengukur tingkat kematangannya dengan judul penelitian “Evaluasi Tata Kelola TI pada Sekretariat DPRD Provinsi Sumatera Selatan menggunakan COBIT 5" 


\section{METODOLOGI PENELITIAN}

\subsection{Model Penelitian}

Metode penelitian yang dipakai oleh penulis adalah Metode Deskriptif, salah satu jenis metode deskriptif adalah metode survey, yaitu penyelidikan yang diadakan untuk memperoleh fakta dari gejala-gejala yang ada dan mencari keterangan secara faktual, baik tetang institusi sosial, ekonomi maupun politik dari suatu kelompok atau daerah [2].

Berikut adalah langkah-langkah Metode Deskriptif yang peneliti pakai untuk melakukan penelitian ini:

1). Memilih dan merumuskan masalah

2). Menentukan tujuan dari penelitian yang akan dikerjakan

3). Membatasi area permasalahan sejauh mana penelitian akan dilaksanakan

4). Merumuskan kerangka teori atau kerangka konseptual

5). Menelurusi sumber-sumber kepustakaan

6). Melakukan kerja lapangan untuk mengumpulkan data

7). Membuat laporan penelitian

\subsection{Cobit 5 Framework}

Control Objectives for Information and related Technology atau disingkat dengan COBIT merupakan suatu panduan untuk melakukan kontrol terhadap informasi, teknologi informasi dan resiko yang terkait. COBIT dikeluarkan oleh ITGI (IT Governance Institute) dan sudah diakui secara internasional [3]. Memiliki 5 domain yaitu;

\section{Evaluate, direct and monitor (EDM)}

Memastikan bahwa tujuan perusahaan dicapai dengan mengevaluasi kebutuhan, kondisi dan pilihan pemangku kepentingan; menetapkan arah melalui penentuan prioritas dan pengambilan keputusan; dan memantau kinerja, kepatuhan dan kemajuan terhadap arah dan tujuan yang disepakati (EDM). EDM memiliki 5 proses yaitu;

01 Ensure governance framework setting and maintenance

02 Ensure benefits delivery

03 Ensure risk optimisation

04 Ensure resource optimisation

05 Ensure stakeholder transparency

2. Align,plan and organise (APO)

Mencakup penggunaan informasi \& teknologi dan bagaimana cara terbaik dapat digunakan di perusahaan untuk membantu mencapai tujuan dan sasaran perusahaan. Ini juga menyoroti bentuk organisasi dan infrastruktur yang harus diambil TI untuk mencapai hasil optimal dan untuk menghasilkan manfaat paling banyak dari penggunaan TI. Tabel berikut mencantumkan proses TI tingkat tinggi untuk domain APO. APO memiliki 13 proses yaitu; 
01 Manage the IT management framework

02 Manage strategy

03 Manage enterprise architecture

04 Manage innovation

05 Manage portofolio

06. Manage budget and costs

07 Manage human resources

08 Manage relationship

09 Manage service agreements

10 Manage suppliers

11 Manage quality

12 Manage risk

13 Manage security

3. Build, acquire and implement (BAI)

Identifikasi persyaratan TI, memperoleh teknologi, dan menerapkannya dalam proses bisnis perusahaan saat ini. Tabel berikut mencantumkan tujuan kontrol tingkat tinggi untuk domain BA. BAI memiliki 10 proses yaitu;

01 Manage programmes and projects

02 Manage requirements definition

03 Manage solutions identification and build

04 Manage availability and capacity

05 Manage organisational change enablement

06 Manage changes

07 Manage change acceptance and transitioning

08 Manage knowledge

09 Manage assets

10 Manage configuration

4. Deliver, Service and support (DSS)

Berfokus pada aspek pengiriman teknologi informasi. Ini mencakup bidangbidang seperti pelaksanaan aplikasi dalam sistem TI dan hasilnya, serta, proses dukungan yang memungkinkan pelaksanaan yang efektif dan efisien dari sistem TI ini. Tabel berikut mencantumkan tujuan kontrol tingkat tinggi untuk domain DSS. DSS memiliki 9 proses yaitu;

01 Manage operations

02 Manage service requests and incidents

03 Manage problems

04 Manage continuity

05 Manage security services

06 Manage business process control 
5. Monitor, evaluate and assess (MEA)

Memantau, Mengevaluasi, dan Menilai penawaran domain dengan strategi perusahaan dalam menilai kebutuhan perusahaan dan apakah sistem TI saat ini masih memenuhi tujuan yang dirancang dan kontrol yang diperlukan untuk mematuhi persyaratan peraturan. Pemantauan juga mencakup masalah penilaian independen terhadap efektivitas sistem TI dalam kemampuannya untuk memenuhi tujuan bisnis dan proses kontrol perusahaan oleh auditor internal dan eksternal. Tabel berikut mencantumkan tujuan kontrol tingkat tinggi untuk domain MEA. MEA memiliki 3 proses yaitu;

01 Monitor, evaluate and assess performance and conformance

02 Monitor, evaluate and assess the system of internal control

03 Monitor, evaluate and assess compliance with externalrequirements

Dengan 5 level yang disediakan [4], yaitu;

1. Level 0 Incomplete, pada level ini organisasi tidak mengetahui sama sekali tentang aktifitas teknologi informasi di organisasinya.

2. Level 1Performed, pada level ini organisasi sudah mengetahui tentang aktifitas teknologi informasi di organisasinya, namun belum menyediakan lingkungan yang stabil untuk melakukan aktifitas operasional teknologi informasi dan mengembangkan suatu produk baru.

3. Level 2 Managed, pada level ini perusahaan sudah mempunyai berbagai kebijakan untuk mengatur berbagai aktifitas operasional dan pengembangan teknologi informasi.

4. Level 3 Established, pada level ini organisasi sudah mempunyai suatu unit kerja beserta struktur organisasinya terkait dengan aktifitas teknologi informasi, sudah mempunyai SOP yang didefinisikan dari kebijakan terkait dengan aktifitas operasional dan pengembangan teknologi informasi.

5. Level 4 Predictable, pada level ini organisasi sudah mampu untuk membuat suatu pengukuran untuk semua kegiatan teknologi informasi,qmampu untuk mengetahui nailai bisnis yang didapat dari teknologi informasi dan mampu untuk menghasilkan suatu produk teknologi informasi yang mempunyai nilai tambah bagi bisnis dan organisasi.

6. Level 5 Optimising, pada level ini teknologi informasi sudah terintegrasi dengan semua aspek aktifitas bisnis dan operasional organisasi. Teknologi informasi telah mampu berinovasi pada semua aspek aktifitas bisnis agar kinerja organisasi menjadi efisien, efektif, transparan dan berkualitas tinggi.

\subsection{Tahapan Penelitian}

1. Tahap identifikasi masalah

Pada tahap ini kegiatan yang dilakukan oleh penulis adalah mengidentifikasi masalah yang ada. Tahapan yang dilakukan adalah: 
a. Penulis melakukan penelitian kecil dengan cara melihat langsung tata kelola IT/IS, melihat sistem yang digunakan dan teknologi apa yang mendukung sistem tersebut.

b. Lalu penulis melakukan diskusi kebeberapa user yang menggunakan sistem untuk mengetahui IT/IS apa yang digunakan, apa fungsinya, bagaimana alur kerja dan prosesnya.

c. Penulis melakukan studi dokumen terhadap SOP yang berlaku saat ini di Sekretariat DPRD Prov Sumsel untuk mengetahui apakah praktik dalam penggunaan IT/IS telah dijalankan sesuai SOP.

d. Setelah tahapan diatas, penulis membuat rangkuman kecil berupa poinpoin masalah yang akan penulis bahas pada penelitian ini.

2. Kajian literatur

Pada tahap ini penulis melakukan kajian-kajian dari teori yang ada tentang evaluasi tata kelola teknologi informasi dan framework Cobit 5 termasuk didalamnya penelitian terdahulu dengantema yang sama. Adapun tahapan kajian literatur yang dilakukan penulis menurut Creswell (2009) adalah:

a. Penulis mengkaji Framework Cobit 5 secara mendalam untuk memetakan domain dan aktivitas yang nantinya akan menjadi instrumen kuesioner sebagai tool dalam mengukur tingkat maturitas tata kelola IT/IS di Sekretariat DPRD Prov Sumsel.

b. Mengakses internet untuk mencari dan mengulas jurnal elektronik yang berkaitan dengan evaluasi tata kelola menggunakan Cobit 5

c. Penulis melakukan bedah buku yang ditulis oleh para ahli di perpustakaan untuk mencari teori-teori pendukung lainnya dalamm enyelesaikan laporan penelitian ini.

d. Menulis kajianp ustaka yang akan penulis cantumkan pada laporan penelitian.

3. Perencanaan Audit Menggunakan Cobit 5

a. Mapping Cobit 5, Mapping cobit merupakan tahapan awal penulis dalam menentukan Objektivitas, Enterprise Goals, IT Related Goals sampaike domain dan proses yang akan penulis gunakan dalam mengevaluasi tata kelola IT/IS. Berikut adalah tahapan dalam pemetaan Cobit:

Enterprise Goals menyediakan 3 objektivitas tata kelola yang dibutuhkan yaitu Benefits Realisation, Risk Optimisation danResource Optimisation. Dalam penelitian ini penulis memilih Resource Optimisation dan memilih kategori P (Primary) dan S (Secondary) untuk mengevaluasi tata kelola IT/Id di DPRD Prov Sumsel.

IT Related Goals menyediakan informasi dan tujuan teknologi yang nantinya akan di petakan bersamaan dengan IT Entersprise Goals. 
Mapping Enterprise Goals to IT Related Goals, pada tahap ini penulis melakukan seleksi terhadap 14 Enterprise Goals (EG) terhadap 17 ITRelated Goals (IT-RG), penulis akan memilih kategori Primary (P) dan S (Secondary) sesuai dengan kebutuhan evaluasi.

Mapping Cobit5 IT - Related Goals to Processes, tahap ini adalah tahap terakhir dalam proses pemetaan, dimana pada tahap ini penulis memilih 37 domain terhadap 17 IT-Related Goals yang telah dipilih, penulis memilih proses yang berkategori Primary (P) dan $\mathrm{S}$ (Secondary) sesuai dengan kebutuhan evaluasi.

Adapun penelitian terdahulu yang penulis pakai sebagai acuan dalam penelitian ini adalah sebagai berikut:

1. Axelon Samuel Renyaan (2013), Pada penelitian ini dijelaskan bahwa Pemerintah kota Salatiga telah lama menggunakan teknologi informasi dalam rangka integrasi berbagai sistem untuk pengelolaan data dan informasi serta layanan di setiap dinas,oleh karena itu dilakukan kajian eveluatif untuk mengukur tingkat kinerja. Peneliti menggunakan framework Cobit 4.1 dan mendapatkan hasil bahwa tata kelola TI pemerintah Salatiga masih berada di level 1 (Initial/Adhoc) yang berarti bahwa pengelolaan TI masih bersifat terpisah dan belum menyatu dengan strategi organisasi [5].

2. R. Aryo Bayu Bimantara (2015), Pada penelitin ini dijelaskan bahwa belum adanya kebijakan tata kelola proyek pengembangan sistem TI yang jelas dan tidak optimalnya fungsi-fungsi dalam pengelolaan proyek pengembangan sistem oleh karena itu dilakukan perancangan tata kelola menggunakan Cobit 5, dan hasilnya adalah tingkat kapabilitas berada di level 1, belum terdapat suatu standar, penerapan standar, metode pengukuran dan optimalisasi proses-proses yang ada pada Bank XYZ [6]. Kerangka berpikir penulis rangkum pada gambar 1 dibawah ini;

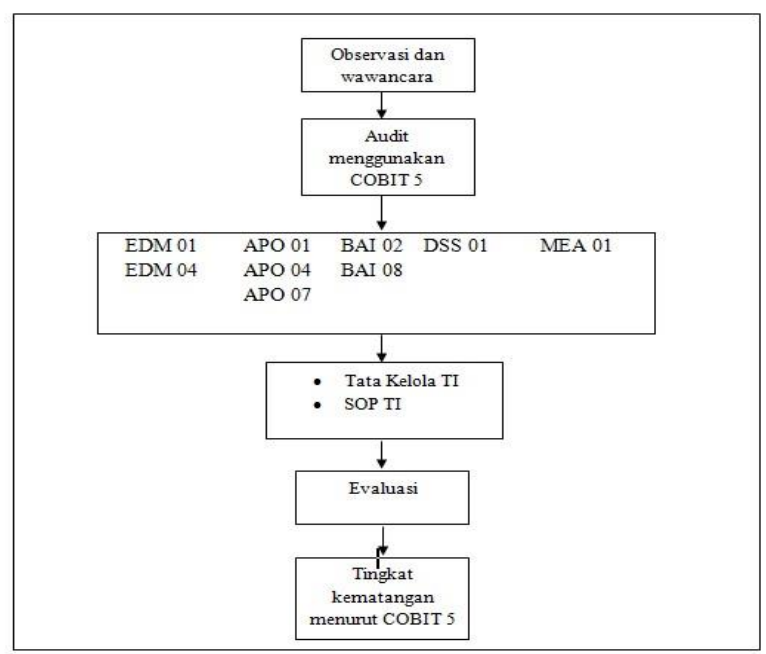

Gambar 1 Kerangka Berpikir 


\section{HASIL DAN PEMBAHASAN}

\subsection{Responden}

Dari hasil penyebaran kuesioner terdapat 30 responden pengguna IT/IS yang telah mengisi pernyataan dengan karakteristik yang ada pada tabel 1 sebagai berikut:

Tabel 1 Karakteristik Responden

\begin{tabular}{|c|c|c|c|c|c|c|c|}
\hline \multicolumn{2}{|c|}{ Jenis Kelamin } & \multicolumn{3}{|c|}{ Pendidikan } & \multicolumn{3}{c|}{ Divisi } \\
\hline $\begin{array}{c}\text { Laki- } \\
\text { laki }\end{array}$ & Perempuan & D3 & S1 & S2 & Umum & Keuangan & Humas \\
\hline 21 & 9 & 9 & 17 & 4 & 5 & 20 & 10 \\
\hline
\end{tabular}

\subsection{Hasil Pemetaan}

Sebelum melakukan evaluasi, terlebih dahulu penulis melakukan pemetaan terhadap COBIT, dari hasil pemetaan tersebut barulah didapat domain-domain yang akan penulis gunakan dalam mengevaluasi. Pemetaan dibuat berdasarkan kebutuhan penelitian yaitu tata kelola IT/IS yang berarti berfokus pada Resource Optimisation berkategori Primary (P), kategori primary adalah aktivitas utama yang disediakan oleh COBIT, sedangkan secondary adalah aktivitas pendukung apabila memang dibutuhkan. Seluruh tahapan pemetaan dipilih kategory primary sesuai dengan kebutuhan penelitian. Tahap pemetaan yang pertama adalah menentukan Enterprise Goals ada pada tabel 2:

Tabel 2 Enterprise Goals

\begin{tabular}{|c|l|c|}
\hline $\begin{array}{c}\text { BSC } \\
\text { Dimension }\end{array}$ & \multicolumn{1}{|c|}{ Enterprise Goals } & $\begin{array}{c}\text { Resources } \\
\text { Optimisation }\end{array}$ \\
\hline Internal & \begin{tabular}{c}
11 Opimisasi fungsi proses bisnis \\
\cline { 2 - 3 }
\end{tabular} & $\begin{array}{l}\text { 14 Produktivitas operasional dan } \\
\text { staf }\end{array}$ \\
\hline
\end{tabular}

Setelah didapat pemetaan Enterprise Goals maka masuk ke tahap yang kedua yaitu melakukan pemetaanterhadapEnterprise Goals to IT-Related Goal untuk menyelaraskan tujuan perusahaan dengan tujuan IT, pemetaan Enterprise Goals to IT-Related Goal. Tahap yang ketiga adalah Mapping IT-Related Goals To Process, dimana penulis telah menentukan domain yang akan digunakan dalam mengevaluasi tata kelola IT/IS, masing-masing domain memiliki aktivitas yang menjadi tools dalam mengevaluasi berbentuk kuesioner.

\subsection{Hasil}

Hasil penelitian yang didapat dari penyebaran kuesioner yang berjumlah 35 pernyataan maka didapatkan tingkat maturitas pada tabel 3 sebagai berikut: 
Tabel 3 Tingkat Maturitas

\begin{tabular}{|c|c|c|c|}
\hline $\begin{array}{l}\text { Domain } \\
\text { Proses }\end{array}$ & Deskripsi Proses & $\begin{array}{c}\text { Tingkat } \\
\text { Kematanga }\end{array}$ & Kondisi \\
\hline EDM 01 & $\begin{array}{c}\text { Memastikan } \\
\text { pengaturan dan } \\
\text { pemeliharaan } \\
\text { kerangka kerja tata } \\
\text { kelola }\end{array}$ & 2.35 & Managed Process \\
\hline EDM 04 & $\begin{array}{c}\text { Memastikan } \\
\text { pengoptimalan sumber } \\
\text { daya }\end{array}$ & 1.90 & Managed Process \\
\hline APO 01 & $\begin{array}{c}\text { Mengelolah kerangka } \\
\text { kerja manajemen TI }\end{array}$ & 0.5 & Incomplete Process \\
\hline APO 04 & Mengatur Inovasi & 3.74 & Predictable Process \\
\hline APO 07 & $\begin{array}{l}\text { Mengelolah sumber } \\
\text { daya manusia }\end{array}$ & 3.13 & Established Process \\
\hline BAI 02 & $\begin{array}{l}\text { Mengelolah definisi } \\
\text { persyaratan }\end{array}$ & 3.06 & Established Process \\
\hline BAI 08 & $\begin{array}{l}\text { Mengelolah } \\
\text { pengetahuan }\end{array}$ & 1.68 & Managed Process \\
\hline DSS 01 & $\begin{array}{c}\text { Mengelolah } \\
\text { operasional }\end{array}$ & 2.15 & Managed Process \\
\hline MEA01 & $\begin{array}{c}\text { Memonitor, mengevaluasi } \\
\text { dan } \\
\text { menilai kinerja }\end{array}$ & 1.65 & Managed Process \\
\hline & Rata-rata Jumlah Indeks & 2.24 & Managed Process \\
\hline
\end{tabular}

Hasil pengukuran tingkat maturitas penulis rangkum dalam sebuah grafik yang menggambarkan level masing-masing domain dimana tingkat maturitas tertinggi ada pada Domain APO 04 dan level terendah ada pada Domain APO 01, bisa dilihat pada gambar 2 dibawah ini: 


\section{Grafik Maturity Lavel}

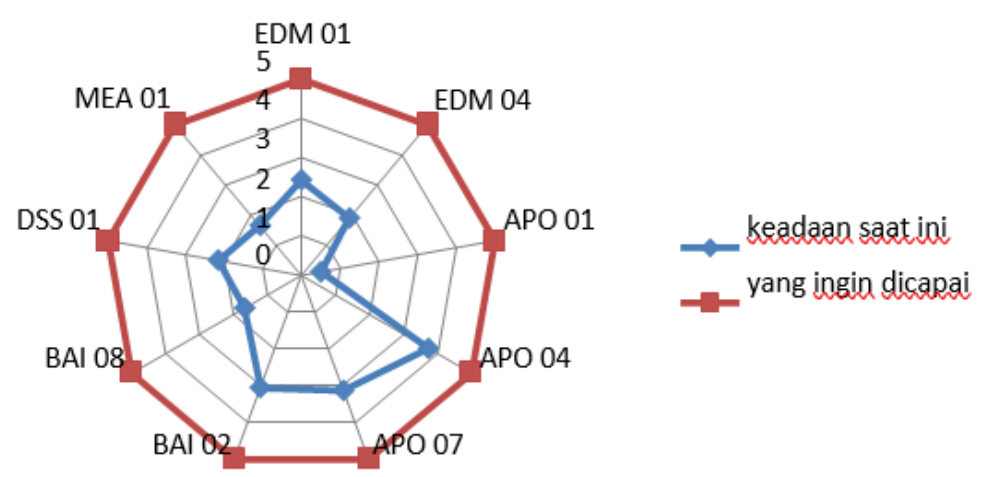

Gambar 2 Grafik Maturity Level

\section{SIMPULAN}

Bedasarkan evaluasi penelitian menggunakan kerangka COBIT 5 di Sekretariat DPRD Sumsel, maka didapat diambil kesimpulan yaitu:

1. Evaluasi tingkat kematangan IT/IS di Sekretariat DPRD Prov Sumsel menggunakan COBIT 5 dengan domain EDM 01, EDM 04, BAI 02, BAI 08, APO 01, APO 04, APO 07, DSS 01 dan MEA 01 telah dilakukan dengan cukup baik.

2. Tingkat kematangan tata kelola IT/IS di Sekretariat DPRD Prov Sumsel adalah 2.24 berada pada level 2 yang berarti bahwa tata kelola IT/IS dilakukan secara Managed Proces.

3. Untuk meningkatkan level kematangan dari level 2 ke level 5 sesuai dengan yang diharapkan dengan tujuan Sekretariat, maka penulis merekomendasikan perbaikan secara keseluruhan sebagai berikut:

Melakukan evaluasi kinerja, proses dan hasil dari IT/IS serta SDM secara rutin menggunakan Framework tertentu, penulis menyarankan penggunaan Framework COBIT atau ITIL.

Rekrut tim khusus yang memiliki kemampuan dalam audit teknologi agar evaluasi tata kelola IT dapat dilakukan tanpa memberikan beban kerja tambahan kepada karyawan lain.

Setelah melakukan pelatihan, pantau user dengan pendekatan monitoring untuk mengetahui letak kebingungan user dalam pengoperasian teknologi.

Buat buku pedoman khusus teknologi, yang berisi fungsi masingmasing menu dan tata cara penggunaannya.

Rancang bangun database internal, lakukan pengintegrasian antar sistem yang saling berkaitan untuk efisiensi waktu dalam menjalankan tugas dan mengurangi kesalahan dalam input data maupun pelaporan.

Segera mungkin dibakukan SOP teknologi yang terintegrasi dengan SOP kepegawaian. 


\section{DAFTAR RUJUKAN}

[1] S. De Haes and W. Van Grembergen, Enterprise Governance of Information Technology. 2009.

[2] Nazir , Mohammad " Metode penelitian / Mohammad," no. 1988, p. 32059, 2019.

[3] ISACA.org, Enabling Processes. 2012.

[4] Isaca, "The Val IT Framework 2.0," 2009.

[5] A. Ilmiah DiaKomputer Halaman Ju, J. Tambotoh, and U. Kristen Satya Wacana Salatiga, "Evaluasi Tata Kelola Teknologi Informasi Menggunakan Kerangka COBIT 4.1 Pada Lembaga Pemerintah (Studi Kasus : Pemerintah Kota Salatiga)," no. 682007077, 2013.

[6] B. Bimantara, "Universitas Indonesia Perancangan Tata Kelola Pada Proyek Pengembangan Sistem Dengan Kerangka Kerja Cobit 5: Studi Kasus Pt Bank Xyz ( Persero ) Tbk Jakarta,” 2015. 